\title{
Simulation of Lovastatin Production in Solid-State Fermentation via Oil Palm Frond
}

\author{
N. A. Nata ${ }^{1}$ F. Mohd Said², S. Md Shaarani@Md Nawi², N. Harun 2*, \\ ${ }^{1}$ Department of Chemical Engineering, University Malaysia Pahang, Lebuhraya Tun Razak, 26300 Pahang, Malaysia. \\ 2Faculty of Chemical and Process Engineering Technology, Universiti Malaysia Pahang, Lebuhraya Tun Razak, 26300 Kuantan, Pahang, Malaysia.
}

\begin{abstract}
Lovastatin is a potent drug for lowering blood cholesterol. It is a competitive inhibitor of 3-hyroxy3-methyl glutaryl coenzyme A (HMG-CoA) reductase, which is a key enzyme in the cholesterol production pathway. Lovastatin increases good cholesterol or high-density lipoproteins to prevent the formation of plaque inside the blood vessels. This study aims to develop a process model of lovastatin produced by Meniscus purpureus under solid-state fermentation using oil palm frond. SuperPro Design V9.5 software was used to develop and simulate the process model. Three parameters which are initial moisture content, the composition of peptone and potassium, were varied to investigate their effects on lovastatin production. The optimum condition simulated using the process model at $\mathrm{pH} 7$ with $60 \%$ initial moisture content, $0.0075 \mathrm{~kg} / \mathrm{hr}$ of potassium and 0.0075 $\mathrm{kg} / \mathrm{hr}$ of peptone was able to produce $0.0288 \mathrm{~kg} / \mathrm{kg}$ of lovastatin. The simulated results show good agreement with experimental work, with a low percentage error of $5.77 \%$, and provide a good approximation on lovastatin yield under various process operating conditions.
\end{abstract}

ARTICLE HISTORY

Received: 31 Jul. 2021

Revised: 13 Sep.2021

Accepted: 28 Sep. 2021

\section{KEYWORDS}

Lovastatin

Solid-state fermentation

SuperPro Design

Simulation

Oil plam frond

\subsection{INTRODUCTION}

Hypercholesterolemia is an abnormally high cholesterol level in the blood that frequently leads to cardiovascular problems. Hypercholesterolemia agents are any substances or compounds that can impede the excess production of cholesterol in the liver. Cardiovascular illnesses are a group of heart and blood vessel problems that can be managed with cholesterol-lowering medications such as statins. Lovastatin is a group of natural statins which are responsible to demolish 3-hydroxy3-methyl glutaryl coenzyme a reductase (HMG-CoA), the reductase inhibitor. Lovastatin is widely used for hypercholesterolemia treatment and reducing cholesterol synthesis [1]. Current industrial production applies submerged fermentation $(\mathrm{SmF})$ to produce lovastatin from fungi.

More recently, there has been growing interest in using the solid-state fermentation (SSF) processing method as an alternative in producing lovastatin due to its numerous advantages [1]. The common substrates used in ssf to produce industrially important bioactive compounds are vegetable and agricultural waste, bran, and bagasse [2]. The optimum conditions to maximize the production of lovastatin derived from oil palm frond (OPF) by monascus purpureus using ssf method was identified at a laboratory scale by Daud et al. [1]. This experimental work successfully proves the capability of OPF to be used as a substrate of lovastatin production and has potential for large scale production. The scale-up of this process is important for manufacturing commercial bioproducts in the industry. The development of a pilot plant is a challenging task due to time and resource constraints. This challenging task can be facilitated by using simulation tools to systemically design and optimize the process for large scale production. This study aims to develop a process model of lovastatin production in SSF by OPF using superpro designer software (SPD). Sensitivity analyses were conducted to investigate the effect of potassium and peptone composition as well as the initial moisture content on the lovastatin yield.

\subsection{PROCESS SIMULATION PROCEDURES}

\subsection{Materials}

The chemical reaction of lovastatin in SSF using OPF is presented in Equation 1 [1]

$$
\begin{gathered}
\mathrm{OPF}+\text { Water + Potassium } \\
\text { Sulphate + Peptone + Oxygen }
\end{gathered}
$$

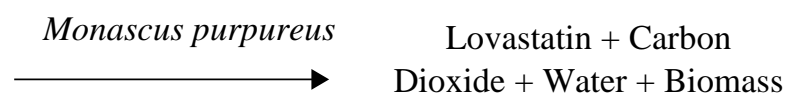

The first step to construct the process flowsheet in SuperPro Designer is the selection of an appropriate mode of operation. The mode of operation selected in the SPD is a batch mode, which considered the sequencing of activities and time-dependency. The next step is specifying the components involved in this process. The components can be searched from the SPD databank, or the user can specify the physical properties in the user databank. Table 1 shows the properties of all components involved in this process. 
Table 1. Properties of Materials [3]

\begin{tabular}{lccccc}
\hline Materials & Formula & $\begin{array}{c}\text { Molecular } \\
\text { Weight } \\
(\mathbf{g} / \mathbf{m o l})\end{array}$ & $\begin{array}{c}\text { Melting Point } \\
\left({ }^{\circ} \mathbf{C}\right)\end{array}$ & $\begin{array}{c}\text { Boiling Point } \\
\left({ }^{\circ} \mathbf{C}\right)\end{array}$ & $\begin{array}{c}\text { Density } \\
\left(\mathbf{k g} / \mathbf{m}^{\mathbf{3}}\right) \\
\mathbf{a t ~ 2 0} \mathbf{C}\end{array}$ \\
\hline Water & $\mathrm{H}_{2} \mathrm{O}$ & 18.0 & 0.0 & 100.0 & 1000 \\
Oxygen & $\mathrm{O}_{2}$ & 16.0 & -219.0 & -183.0 & 1.429 \\
Potassium Sulphate & $\mathrm{K}_{2} \mathrm{SO}_{4}$ & 174.3 & 1067.0 & 1689.0 & 2660 \\
OPF & $\mathrm{CH} 0.108 \mathrm{~N}^{\circ} .09 \mathrm{~S} 0.003 \mathrm{O} 0.793$ & 26.2 & - & - & 700.0 \\
Carbon Dioxide & $\mathrm{CO}_{2}$ & 44.0 & -56.6 & -79.0 & 1.980 \\
Biomass & $\mathrm{CH}_{1.8} \mathrm{O}_{0.5} \mathrm{~N}_{0.2}$ & 24.63 & -273.15 & 526.85 & 1050 \\
Lovastatin & $\mathrm{C}_{24} \mathrm{H}_{36} \mathrm{O}_{5}$ & 404.5 & 174.5 & 559.2 & - \\
\hline
\end{tabular}

\subsection{Process Flowsheet}

The process flow of lovastatin production consists of two main sections; reaction and separation section. It consists of five-unit procedures, namely mixer, heat exchanger, fermenter, rotary vacuum filter and distillation column as shown in Figure 1. All the raw materials are mixed in the mixer (M-101) and undergo pre-treatment by heating the components at $120{ }^{\circ} \mathrm{C}$. The mixing components will then passed through a heat exchanger (E-101) to cool the temperature to $30^{\circ} \mathrm{C}$. After that, the fermentation process takes place in the fermenter (R-101) for eight days with the presence of fungus to speed up the reaction process. The separation process will then started with a rotary vacuum filter (F-101) to remove the biomass in a solid phase and to the distillation column (T-101) for purification. All the unit procedures are connected by adding the streams to represent material transfers. Types of streams can be classified into three, which are feed streams, intermediate streams, and product streams.

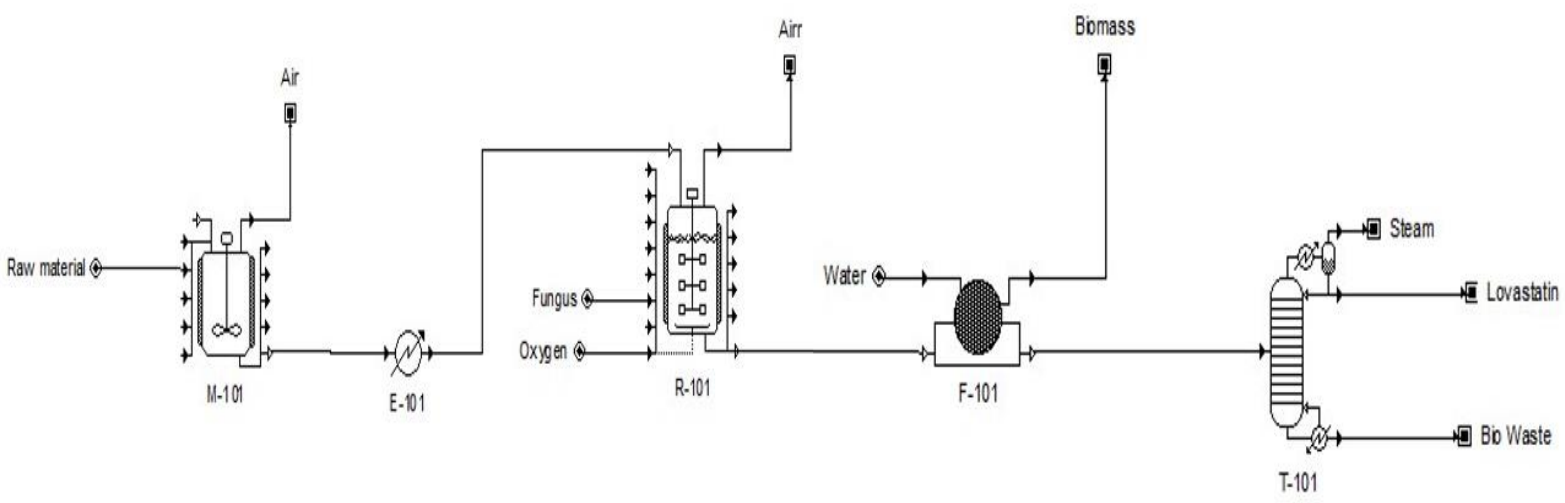

Figure 1. Process flowsheet of lovastatin production

The operating sequence in the mixer involved five stages; charge with raw material, agitation for 10 minutes at room temperature $\left(25^{\circ} \mathrm{C}\right)$, batch heating to $121^{\circ} \mathrm{C}$, batch cooling to $60{ }^{\circ} \mathrm{C}$, transfer out and in place cleaning to complete the mixing process. The mixing components were transferred to the heat exchanger to cooling down the mixing mixture to $30^{\circ} \mathrm{C}$ before fermentation with fungus which sensitive to high temperature. In the fermenter, it involved three operations which are pull in the mixed raw material, batch stock fermentation with present of fungus in room temperature for eight days and in place cleaning to cleaning the unit operation. For the rotary vacuum filter, it involved two operations which are rotary vacuum filter to separate solid (biomass) and liquid phase, and in place cleaning to cleaning the unit operation. Main product which is lovastatin was separated from other impurities in the distillation column. The distillation column is specified with eight stages, $80 \%$ stage efficiency, column pressure at $1 \mathrm{~atm}$, and partial type of condenser.

\subsection{Case Study}

The process operating conditions for the unit procedures involved were specified for model validation and results analysis. In this work, experimental data reported by Daud et al. [1] were used was shown in Table 2. These include the initial moisture content percentage and the potassium and peptone compositions and percentages. The $\mathrm{pH}$ value for these sets of data was at 7 . 
Table 2. Experimental data for model validation and results analysis [1]

\begin{tabular}{cccccccr}
\hline Run & OPF & $\begin{array}{c}\text { Moisture } \\
\text { Content } \\
(\%)\end{array}$ & $\begin{array}{c}\text { Potassium } \\
(\mathrm{kg} / \mathrm{hr})\end{array}$ & $\begin{array}{r}\text { Peptone } \\
(\mathrm{kg} / \mathrm{hr})\end{array}$ & $\begin{array}{c}\text { Yield of Lovastatin } \\
(\text { Experimental }) \\
(\mathrm{kg} / \mathrm{kg})\end{array}$ & $\begin{array}{c}\text { Yield of Lovastatin } \\
(\text { Simulation }) \\
(\mathrm{kg} / \mathrm{kg})\end{array}$ & $\begin{array}{c}\text { Error } \\
(\%)\end{array}$ \\
\hline 1 & 0.0188 & 50 & 0.0075 & 0.0019 & 0.0137 & 0.0153 & 9.98 \\
$\mathbf{2}$ & $\mathbf{0 . 0 1 8 8}$ & $\mathbf{6 0}$ & $\mathbf{0 . 0 0 7 5}$ & $\mathbf{0 . 0 0 7 5}$ & $\mathbf{0 . 0 3 0 5}$ & $\mathbf{0 . 0 2 8 8}$ & $\mathbf{5 . 7 7}$ \\
3 & 0.0188 & 50 & 0.0075 & 0.0131 & 0.0254 & 0.0235 & 8.16 \\
\hline
\end{tabular}

\subsection{RESULT AND DISCUSSION}

\subsection{Model validation}

The process model was validated by calculating the per cent deviation of lovastatin yield between simulation result and experimental data. Table 2 shows the per cent deviation for the three sets of data. Run 2 shows the lowest percentage error while Run 1 shows the highest percentage error with $5.77 \%$ and $9.98 \%$, respectively. Overall, the percent difference between experimental data and simulation results was less than $10 \%$. It shows a reasonable agreement with the experimental data. The maximum lovastatin production via SSF was $0.0288 \mathrm{~kg} / \mathrm{kg}$ at $60 \%$ initial moisture content, 0.0075 $\mathrm{kg} / \mathrm{hr}$ of potassium and $0.0075 \mathrm{~kg} / \mathrm{hr}$ of peptone.

\subsection{Sensitivity analysis}

Several simulation results were generated to evaluate the effects of potassium and peptone composition and percentage of initial moisture content on lovastatin yield. Figure 2 depicts the simulation results at various process conditions. As depicted in Figure 2, the highest yield of lovastatin was obtained at $0.0075 \mathrm{~kg} / \mathrm{hr}$ potassium, $0.0075 \mathrm{~kg} / \mathrm{hr}$ peptone and initial moisture content of $60 \%$. This is the optimum condition to produce the maximum yield of lovastatin.

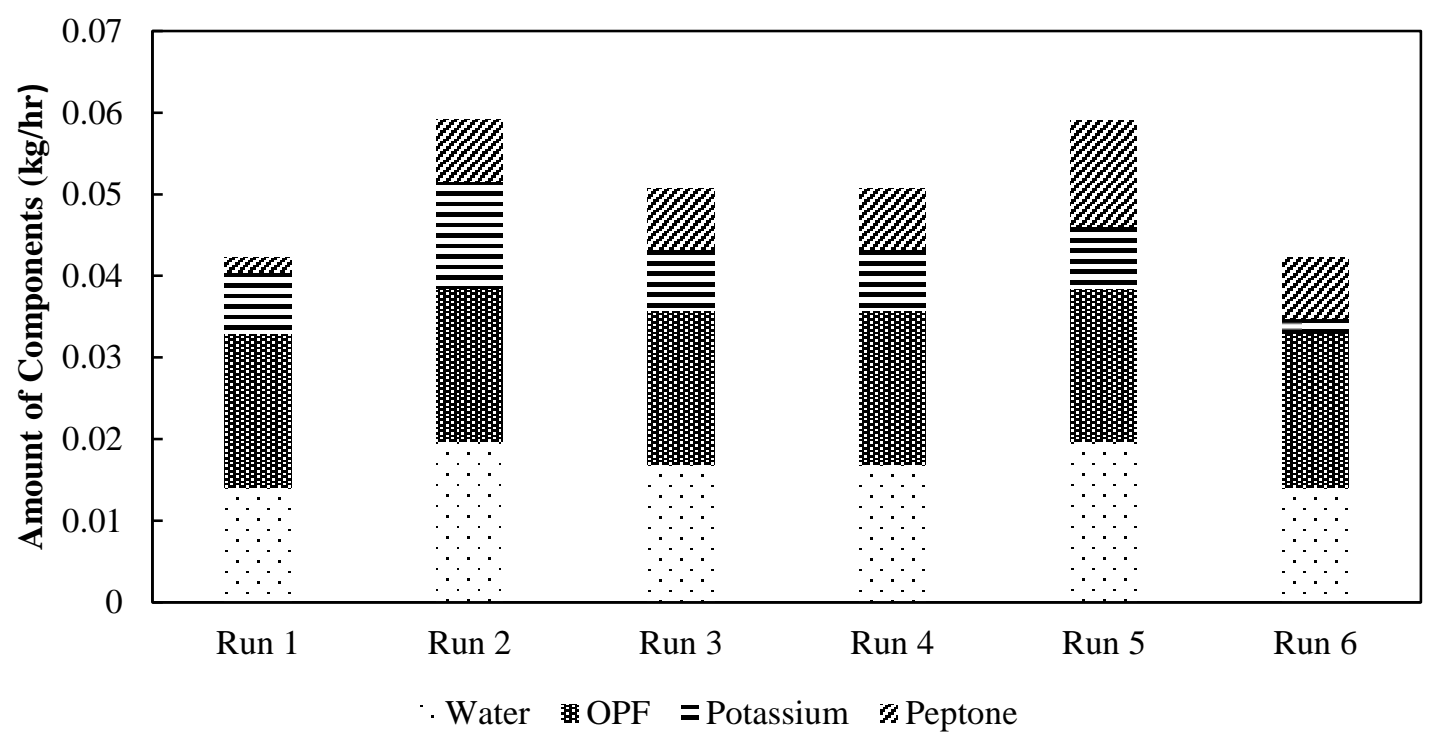

Figure 2. Lovastatin production at various operating conditions

\subsection{Effect of initial moisture content}

As shown in Figure 2, a higher initial moisture content resulted in high lovastatin production, when the potassium and peptone are kept constant. It can be clearly seen when comparing the operating conditions of run 3 and run 4 . The Monascus purpureus was able to utilize the substrate at the optimum initial moisture content of $60 \%$. These results are consistent with that of Li et al. [4] which produced more Monacolin K (MK) by SSF at higher initial moisture content. The moisture content of the substrate is crucial for controlling nutrient diffusions in the reaction procedure, sustaining the stability and the biological functions of biomolecules such as nucleotides, proteins and carbohydrates [5]. The substrate porosity is determined by the initial moisture content [6]. The porosity of the substrate will reduce and cause the mass transfer process like oxygen diffusion to decrease if the initial moisture content of the substrate exceeds the optimum value. On the contrary, metabolite production can decline at low initial moisture content due to a lower degree of substrate swelling and sub-optimal growth [7].

\subsection{Effect of potassium composition}

Potassium is an essential nutrient for fungal growth and might contribute to lovastatin production [8]. The results from run 2 and 6 in Figure 2 shows that increasing the potassium composition has decreased lovastatin yield. It is believed that 
this trend happens when the potassium composition exceeded the optimum condition, which is $0.0075 \mathrm{~kg} / \mathrm{kg}$. Lower initial moisture content and lower potassium composition in run 6 compared to the optimum condition in run 3 also cause the lovastatin yield to decline. Interaction of these two factors has affected the fungal growth and consequently reduces lovastatin production. Apart from these factors, $\mathrm{pH}$ and minerals are also essential in lovastatin production [1,9].

\subsection{Effect of peptone composition}

The effect of peptone composition is analysed from run 1 and 5 in Figure 2. It shows that the increase of peptone composition enhanced the lovastatin yield. Peptone act as an organic nitrogen source, an important element for the growth and metabolism of fungal. It can be a limiting factor in the production of microbial metabolites [10]. Due to the longer biosynthesis of lovastatin, peptone was preferred as an organic nitrogen source. In comparison to inorganic nitrogen sources, organic nitrogen sources include more complex nutrients [11]. The amount of carbon and nitrogen in the fermentation medium are important elements in the manufacture of lovastatin because they act as precursors and cofactors in the development of biomass and the lovastatin product [12]. Higher peptone concentrations added in the medium affected the Monascus purpureus growth by shortening the growth period and allowing for a faster transition to the stable phase, thus letting the product be synthesis [4].

\subsection{CONCLUSION}

In conclusion, the optimum condition to maximize the lovastatin yield using Monascus purpureus under SSF was $0.0075 \mathrm{~kg} / \mathrm{hr}$ of peptone, $0.0075 \mathrm{~kg} / \mathrm{hr}$ of potassium and $60 \%$ initial moisture content. The process model was simulated at $\mathrm{pH} 7$ using SPD. The lovastatin yield produced was $0.0288 \mathrm{~kg} / \mathrm{kg}$ at the optimum condition. Process model validation under the optimal condition resulted in $5.77 \%$ error between simulation and experimental data. The results confirmed the adequacy of the process model to predict lovastatin production. Two important parameters that affected the lovastatin yield were initial moisture content and peptone composition. The process model can further be used for the technoeconomic study of lovastatin production under SSF using oil palm frond.

\section{ACKNOWLEDGEMENT}

The authors would like to thank the Universiti Malaysia Pahang (UMP) for the financial support through research grant PGRS1903115.

\section{REFERENCES}

[1] N. F. S. Daud, F. M. Said and J. M. Ho, “Optimization of Lovastatin in Solid-State Fermentation using Oil Palm Frond,” IOP Conf. Ser.: Mater. Sci. Eng. 736 022056, 2020, doi: 10.1088/1757-899X/736/2/022056.

[2] V. C. Renge, S. V. Khedkar, N. R. Nandurkar, "Enzyme Synthesis by Fermentation Method : A Review," Sci. Revs. Chem. Commun., 2(4), 585-590, 2012.

[3] W. G. Don, H. P. Robert, "Perry's Chemical Engineers' Handbook (8th ed.)," New York: McGraw-Hill, 2008.

[4] L. P. Li, B. B. Zhang, G. R. Xu, "Efficient conversion of high concentration of glycerol to Monacolin K by solidstate fermentation of Monascus purpureus using bagasse as carrier," Bioprocess and biosystems engineering, 36(3), 293-299, 2013.

[5] B. J. Xu, Q. J. Wang, X. Q. Jia, C. K. Sung, "Enhanced lovastatin production by solid state fermentation of Monascus ruber," Biotechnology and bioprocess engineering, 10(1), 78-84, 2005

[6] K. Y. Jeong, J. E. Altland, "Initial Substrate Moisture Content Affects Chemical Properties of Bagged Substrates Containing Controlled Release Fertilizer at Two Different Temperatures," Hortscience, 52(10), 1429-1434, 2017, doi: 10.21273/HORTSCI12216-17

[7] N. Mahanta, A. Gupta, S. K. Khare, "Production of protease and lipase by solvent tolerant Pseudomonas aeruginosa PseA in solid-state fermentation using Jatropha curcas seed cake as substrate," Bioresource Technology, 99, 17291735, 2008.

[8] P. M. Latha, P. Chanakya, M. Srikanth, "Lovastatin production by Aspergillus fischeri under solid state fermentation from coconut oil cake," Nepal Journal of Biotechnology, 2(1), 26-36, 2012.

[9] M. F. Jahromi, J. B. Liang, Y. W. Ho, R. Mohamad, Y. M. Goh, P. Shokryazdan, "Lovastatin production by Aspergillus terreus using agro-biomass as substrate in solid state fermentation," Journal of biomedicine \& biotechnology,196264, 2012, doi: 10.1155/2012/196264.

[10] M. Chandrasekaran, P. Lashmanaperumalsamy, D. Chandramohan, "Combined effect of environmental factors on spoilage bacteria," Fish Technology, 28, 146-153, 1991.

[11] B. B. Zhang, H. B. Xing, B. J. Jiang, L. Chen, G. R. Xu, Y. Jiang, D. Y. Zhang, "Using millet as substrate for efficient production of monacolin $\mathrm{K}$ by solid-state fermentation of Monascus ruber," Journal of bioscience and bioengineering, 125(3), 333-338, 2018

[12] A. S. Vidyarthi, B. Bhunia, T. Mandal, "A review on lovastatin and its production," Journal of biochemical technology, 4(1), 581-587, 2013. 